\title{
No association between IRS-1 promoter methylation and type 2 diabetes
}

\author{
JIANGBO MA ${ }^{1 *}$, JIA CHENG $^{2,3^{*}}$, LINGYAN WANG $^{4 *}$, HONGWEI WANG $^{5}$, LEITING XU $^{2,3}$, \\ PANPAN LIU ${ }^{2,3}$, SHIZHONG BU ${ }^{3}$, LINAZHANG ${ }^{2,3}$, YANPING LE ${ }^{2,3}$, MENG YE $^{2}$, \\ QINWEN WANG $^{2,3}$, YUPING SHI ${ }^{6}$ and SHIWEI DUAN ${ }^{2,3}$
}

\author{
${ }^{1}$ Zhejiang Provincial People's Hospital, Hangzhou, Zhejiang 310014; ${ }^{2}$ The Affiliated Hospital, School of Medicine, \\ Ningbo University, Ningbo, Zhejiang 315000; ${ }^{3}$ Zhejiang Provincial Key Laboratory of Pathophysiology, Ningbo University, \\ Ningbo, Zhejiang 315211; ${ }^{4}$ Bank of Blood Products, Ningbo No. 2 Hospital, Ningbo, Zhejiang 315010, P.R. China; \\ ${ }^{5}$ Section of Endocrinology, The University of Chicago Pritzker School of Medicine, Chicago, IL 60637, USA; \\ ${ }^{6}$ Second Affiliated Hospital of Zhejiang University College of Medicine, Hangzhou, Zhejiang 310009, P.R. China
}

Received March 5, 2013; Accepted June 24, 2013

DOI: $10.3892 / \mathrm{mmr} .2013 .1569$

\begin{abstract}
As a candidate gene for type 2 diabetes (T2D), insulin receptor substrate-1 (IRS-1) gene variations were found to be associated with the risk of T2D. The aim of our study was to investigate the contribution of promoter DNA methylation of the IRS-1 gene to the risk of T2D. Using bisulphite pyrosequencing technology, the DNA methylation levels of $3 \mathrm{CpG}$ dinucleotides within the IRS- 1 gene promoter were measured in 48 T2D patients and 48 age- and gender-matched healthy controls. Our results indicated that there was no significant association between the methylation of the IRS-1 gene promoter and the risk of T2D $(\mathrm{P}>0.1)$. A breakdown analysis by gender revealed that $I R S-1$ promoter methylation was not associated with an increased risk of T2D for either gender $(\mathrm{P}>0.1)$, although there were significantly lower methylation levels of $\mathrm{CpG} 1(\mathrm{P}=0.002)$ and $\mathrm{CpG} 2(\mathrm{P}=0.043)$ within the IRS-1 gene promoter in males than in females.
\end{abstract}

Correspondence to: Professor Shiwei Duan, Ningbo University, Ningbo, School of Medicine, 818 Fenghua Road, Jiangbei, Zhejiang 315211, P.R. China

E-mail: duanshiwei@nbu.edu.cn

Dr Yuping Shi, The Second Affiliated Hospital of Zhejiang University, College of Medicine, 88 Jiefang Road, Hangzhou, Zhejiang 310009, P.R. China

E-mail: shiyuping007@hotmail.com

*Contributed equally

Abbreviations: T2D, type 2 diabetes; IRS-1, insulin receptor substrate 1; FTO, fat mass and obesity associated; OR, odd ratios; CI, confidence interval; ALT, alanine aminotransferase; IGT, impaired glucose tolerance

Key words: insulin receptor substrate 1, type 2 diabetes, DNA methylation, promoter

\section{Introduction}

A total of 371 million people worldwide are estimated to have diabetes. Type 2 diabetes (T2D) accounts for $90 \%$ of diabetes worldwide, and this epidemic has become a major challenge $(1,2)$. T2D is caused by impaired insulin secretion and/or impaired peripheral insulin resistance (3). T2D complications consist of blindness, cardiovascular disease, neurological and renal abnormalities that are mortiferous and result in disabling problems (4). The most generally accepted hypothesis is that T2D is a polygenic disease resulting from the interaction of several genetic and environmental factors (5). However, little is known regarding the mechanisms for these environmental factors in T2D pathogenesis through the genetic pathway.

As an epigenetic mechanism, the methylation of promoter DNA is capable of stably altering gene expression $(5,6)$. DNA methylation usually suppresses target gene expression $(6,7)$. It has been suggested that DNA methylation contributes to the interaction between environmental stressors and genetic factors $(5,6,8)$. Furthermore, epigenetic changes may provide the connection between environmental exposure and individual genetic background (5). Aberrant DNA methylation of a variety of genes was observed in diabetic islets (5). These epigenetic abnormalities may be involved in the pancreatic $\beta$-cell functionality, apoptosis and adaptation to environmental metabolic stress, and eventually lead to T2D $(5,6)$.

The interaction between genetic and environmental factors may be reflected by modifying the methylation of promoter DNA in metabolic disorders (6). Recently, T2D-related epigenetic imbalance of the human genome was found in pancreatic islets (5), skeletal muscle (6), adipose tissues (6) and peripheral blood (9). Fat mass- and obesity-associated (FTO) gene hypomethylation may indicate a significantly increased risk of T2D in young individuals (9). Epigenetic studies on T2D have unlocked the mechanisms for the correlation between individual predisposition and genetic characters (9).

Insulin receptor substrate-1 (IRS-1) has a marked effect on the transmission process from insulin and insulin-like growth 
factor-1 receptors to the intracellular signaling pathways of glycometabolism (10). IRS-1 gene variants have been associated with insulin-resistance as well as with the increased risk of major adverse cardiovascular events in T2D $(11,12)$. IRS proteins have been considered to play broad roles in the common regulatory path to diabetes (10). According to previous findings regarding the contribution of DNA methylation to the risk of T2D, we assessed the differences in the methylation levels of the IRS-1 gene promoter between T2D patients and their healthy counterparts. These results may clarify the epigenetic role of the IRS-I gene in the pathogenesis of T2D.

\section{Materials and methods}

Subjects. This study comprised 48 T2D cases and 48 controls from the Zhejiang Provincial People's Hospital and the Affiliated Hospital of Ningbo University. Detailed patient characteristics are provided in Table I. All the individuals are Han Chinese who have resided in Zhejiang for at least three generations. T2D patients were recruited if they had a fasting plasma glucose concentration of $\geq 7.0 \mathrm{mmol} / 1$ or plasma glucose levels of $\geq 11.1 \mathrm{mmol} / 12 \mathrm{~h}$ after a standard glucose challenge (1). Healthy control individuals were recruited with standard fasting blood glucose levels of $<6.1 \mathrm{mmol} / 1$. None of the controls had a family history of T2D in first-degree relatives or had received any drug therapy. Subjects were excluded from this study if they had hypertension, coronary heart disease, renal inadequacy, drug abuse or a serious disease. The present study was approved by the Ethics Committee of Ningbo University and written informed consent was obtained from all subjects. Blood samples were collected in $3.2 \%$ citrate sodium-treated tubes and subsequently stored at $-80^{\circ}$ for DNA extraction.

Phenotype collection. Blood samples were obtained following a 12-h overnight fast from the antecubital vein into vacutainer tubes containing EDTA. Plasma levels of cholesterol, triglyceride, alanine aminotransferase (ALT), uric acid and glucose were enzymatically measured using a CX7 analyzer (Beckman, Fullerton, CA, USA).

DNA preparation and methylation assay. Human genomic DNA was isolated from peripheral blood samples using the nucleic acid extraction automatic analyzer (Lab-Aid 820, Zeesan, Xiamen, China). DNA was quantified using the PicoGreen ${ }^{\circledR}$ double-strand (dsDNA) DNA quantification kit (Molecular Probes, Inc., Eugene, OR, USA). Bisulphite pyrosequencing technology was used to determine the methylation levels of $3 \mathrm{CpG}$ dinucleotides on the fragment (chr2:227662980-227663002) within the IRS-1 promoter (Fig. 1). Pyrosequencing assays combined sodium bisulfite DNA conversion chemistry, polymerase chain reaction (PCR) amplification and sequencing by synthesis assay of the target sequence. Sodium bisulfite preferentially deaminated unmethylated cytosine residues to thymines (following PCR amplification), whereas methyl-cytosines remained unmodified. PCR primers were selected by using PyroMark Assay Design software v2.0.1.15. The PCR and pyrosequencing primers for IRS- 1 gene promoter amplification are described in Table II.
Table I. Patient characteristics.

\begin{tabular}{lcc}
\hline Characteristics & Mean \pm SE & Range \\
\hline Age $($ years $)$ & $59.2 \pm 7.5$ & $(35.0-69.0)$ \\
Gender $(\mathrm{M} / \mathrm{F})$ & $48 / 48$ & \\
BMI $\left(\mathrm{kg} / \mathrm{m}^{2}\right)^{\mathrm{a}}$ & $23.71 \pm 3.28$ & $(17.15-42.96)$ \\
Total cholesterol $(\mathrm{mmol} / \mathrm{l})$ & $5.19 \pm 0.96$ & $(2.95-7.90)$ \\
Total triglycerides $(\mathrm{mmol} / \mathrm{l})$ & $1.60 \pm 1.36$ & $(0.40-9.92)$ \\
Glucose $(\mathrm{mmol} / \mathrm{l})$ & $6.76 \pm 2.65$ & $(4.38-22.84)$ \\
ALT $(\mathrm{IU} / \mathrm{l})$ & $21.50 \pm 15.90$ & $(5.00-99.00)$ \\
Uric acid $(\mu \mathrm{mol} / \mathrm{l})$ & $294.90 \pm 81.10$ & $(132.00-531.00)$ \\
CpG1 & $83.16 \pm 5.03$ & $(60.00-91.00)$ \\
CpG2 & $84.61 \pm 4.39$ & $(63.00-91.00)$ \\
CpG3 & $92.49 \pm 6.33$ & $(58.00-100.00)$ \\
\end{tabular}

${ }^{\mathrm{a}} \mathrm{n}=86$ (39 males vs. 47 females). SE, standard error; M, male; F, female; ALT, alanine aminotransferase; BMI, body mass index.

Table II. Primers for insulin receptor substrate-1 promoter methylation analysis.

\begin{tabular}{ll}
\hline Forward: & 5'-AGGTTGGGGAGGATTTGAG-3' \\
Reverse: & 5'-Biotin-ATCTAACCCAAACCCTTAAA \\
& CTT-3' \\
Sequencing: & 5'-GGGGAGGATTTGAGT-3' \\
\hline
\end{tabular}

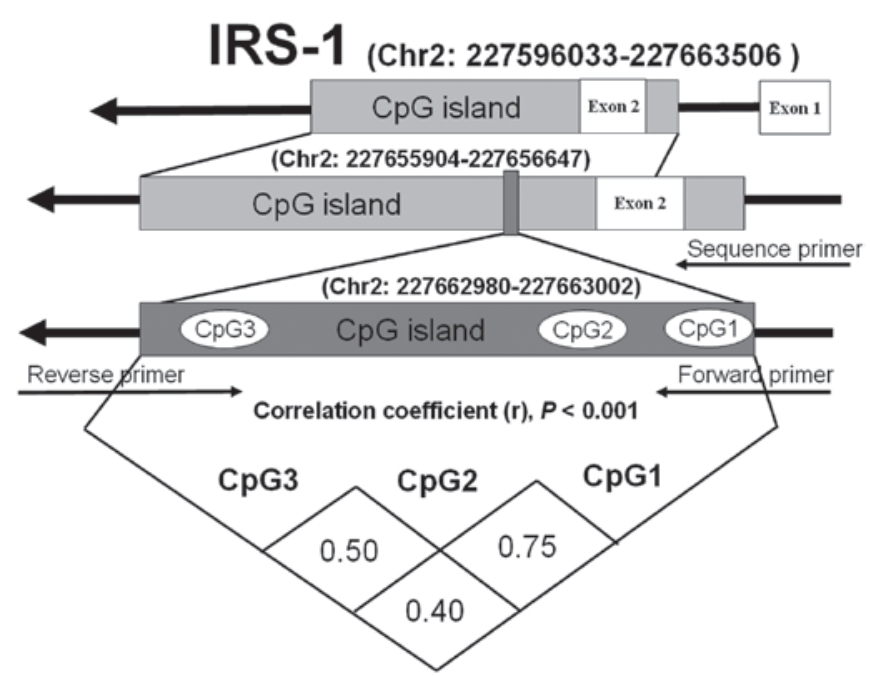

Figure 1. The $\mathrm{CpG}$ islands on the fragment within insulin receptor substrate-1 IRS-1 promoter.

Statistical analysis. Pearson's Chi-square test was used to compare categorical variables and mean group differences. Continuous variables were compared using the Student's t-test. Using Pearson's correlation analysis, the association between IRS-1 DNA methylation and the metabolic features of subjects was determined. $\mathrm{P}<0.05$ was considered to indicate a statistically significant difference. Statistical analyses were performed using PASW Statistics 18.0 software (SPSS, Inc., Somers, NY, USA). 
Table III. Patient characteristics according to gender.

\begin{tabular}{lccc}
\hline Characteristics & Males $(\mathrm{n}=48)$, mean \pm SE & Females $(\mathrm{n}=48)$, mean \pm SE & P-value \\
\hline Age $($ years $)$ & $59.10 \pm 8.60$ & $59.40 \pm 6.30$ & 0.850 \\
BMI $\left(\mathrm{kg} / \mathrm{m}^{2}\right)^{\mathrm{a}}$ & $24.12 \pm 4.03$ & $23.37 \pm 2.49$ & 0.292 \\
Total cholesterol $(\mathrm{mmol} / \mathrm{l})$ & $4.96 \pm 0.94$ & $5.43 \pm 0.93$ & 0.015 \\
Total triglycerides $(\mathrm{mmol} / \mathrm{l})$ & $1.59 \pm 1.28$ & $1.61 \pm 1.45$ & 0.959 \\
Glucose $(\mathrm{mmol} / \mathrm{l})$ & $6.77 \pm 3.07$ & $6.76 \pm 2.19$ & 0.995 \\
ALT $(\mathrm{IU} / \mathrm{l})$ & $25.80 \pm 20.60$ & $17.30 \pm 7.40$ & 0.009 \\
Uric acid $(\mu \mathrm{mol} / \mathrm{l})$ & $325.60 \pm 79.00$ & $264.30 \pm 71.60$ & 0.000 \\
CpG1 & $81.58 \pm 5.53$ & $84.73 \pm 3.94$ \\
CpG2 & $83.71 \pm 4.50$ & $85.52 \pm 4.13$ \\
CpG3 & $92.42 \pm 7.66$ & $92.56 \pm 4.70$ \\
\hline
\end{tabular}

${ }^{\mathrm{a}} \mathrm{n}=86$ (39 males vs. 47 females). SE, standard error; ALT, alanine aminotransferase; BMI, body mass index.

Table IV. Patient characteristics according to the previous history of diabetes $(n=96)$.

\begin{tabular}{lccc}
\hline Characteristics & $\begin{array}{c}\text { Diabetics } \\
(\mathrm{n}=48), \text { mean } \pm \text { SE }\end{array}$ & $\begin{array}{c}\text { Non-diabetics } \\
(\mathrm{n}=48), \text { mean } \pm \text { SE }\end{array}$ & $59.20 \pm 7.50$ \\
\hline Age $($ years $)$ & $59.20 \pm 7.50$ & $23.18 \pm 1.64$ & 1.000 \\
BMI $\left(\mathrm{kg} / \mathrm{m}^{2}\right)^{\mathrm{a}}$ & $24.17 \pm 4.18$ & $5.05 \pm 1.06$ & 0.146 \\
Total cholesterol $(\mathrm{mmol} / \mathrm{l})$ & $5.34 \pm 0.83$ & $1.31 \pm 0.82$ & 0.140 \\
Total triglycerides $(\mathrm{mmol} / \mathrm{l})$ & $1.90 \pm 1.69$ & $5.22 \pm 0.92$ & 0.034 \\
Glucose $(\mathrm{mmol} / \mathrm{l})$ & $8.31 \pm 2.91$ & $18.00 \pm 12.10$ & 0.000 \\
ALT $(\mathrm{IU} / \mathrm{l})$ & $25.10 \pm 18.50$ & $300.60 \pm 90.90$ & 0.028 \\
Uric acid $(\mu \mathrm{mol} / \mathrm{l})$ & $289.30 \pm 70.50$ & $83.71 \pm 4.35$ & 0.499 \\
CpG1 & $82.60 \pm 5.63$ & $85.29 \pm 3.37$ & 0.285 \\
CpG2 & $83.94 \pm 5.17$ & $92.19 \pm 4.16$ & 0.132 \\
CpG3 & $92.79 \pm 7.96$ & 0.643
\end{tabular}

${ }^{\mathrm{a}} \mathrm{n}=86$ (46 diabetics vs. 40 non-diabetics). SE, standard error; ALT, alanine aminotransferase; BMI, body mass index.

\section{Results}

A total of 48 cases of T2D and 48 age- and gender-matched controls were recruited in this study. We found $3 \mathrm{CpG}$ dinucleotides within the IRS- 1 gene promoter and correlation of DNA methylation levels among the CpGs is shown in Fig. 1 ( $r=0.75$, 0.50 and 0.45 ). Patient characteristics are shown in Table I. We explored the association between IRS-1 promoter methylation levels in all the subjects and genders. Our results revealed that CpG1 and CpG2 of the IRS- 1 gene promoter had significantly higher methylation in females compared with males (CpG1, $\mathrm{P}=0.002 ; \mathrm{CpG} 2, \mathrm{P}=0.043$ ) (Table III). Furthermore, the total cholesterol levels in male subjects were significantly lower $(\mathrm{P}=0.015)$ than in females, and the ALT levels of male subjects were significantly higher than in females $(\mathrm{P}=0.009)$.

The total triglyceride levels of T2D subjects were higher compared with those of the controls $(\mathrm{P}=0.034)$. Significant differences in ALT levels were observed between the T2D subjects and the controls $(\mathrm{P}=0.028)$. No differences were observed for the $I R S-1$ gene promoter DNA methylation (including CpG1-3) between the T2D subjects and healthy controls $(\mathrm{P}>0.05)$. A breakdown analysis by gender was unable to determine a significant correlation between the occurence of T2D and DNA methylation of the IRS-1 promoter (CpG1-3) for either gender (Table V). Notably, there was a significantly higher ALT level in female T2D subjects compared with the healthy female controls $(\mathrm{P}=0.019)$. By contrast, a similar ALT level was found between T2D cases and healthy controls in the male subgroup $(\mathrm{P}=0.119)$. This gender-specific difference of ALT levels may be useful in identifying the precise sexual disparity for T2D development and hepatic function for future studies.

\section{Discussion}

T2D is a heterogeneous disease with multiple etiological factors such as genetic risk, diet and physical activity $(3,12)$. The interaction of these factors results in pancreatic $\beta$-cell failure so that insulin secretion is not capable of compensating for peripheral insulin resistance, insulin secretion 
Table V. Patient characteristics by gender.

\begin{tabular}{|c|c|c|c|}
\hline Characteristics & $\begin{array}{c}\text { Diabetic } \\
\text { mean } \pm \mathrm{SE}\end{array}$ & $\begin{array}{c}\text { Non-diabetic } \\
\text { mean } \pm \text { SE }\end{array}$ & P-value \\
\hline \multicolumn{4}{|l|}{ Men $(n=48)$} \\
\hline Age (years) & $59.10 \pm 8.70$ & $59.10 \pm 8.70$ & \\
\hline $\operatorname{BMI}\left(\mathrm{kg} / \mathrm{m}^{2}\right)^{\mathrm{a}}$ & $24.92 \pm 5.17$ & $23.10 \pm 1.21$ & 0.124 \\
\hline Total cholesterol (mmol/l) & $5.06 \pm 0.74$ & $4.86 \pm 1.11$ & 0.464 \\
\hline Total triglycerides $(\mathrm{mmol} / \mathrm{l})$ & $1.81 \pm 1.56$ & $1.38 \pm 0.90$ & 0.254 \\
\hline Glucose (mmol/l) & $8.59 \pm 3.49$ & $4.94 \pm 0.34$ & 0.000 \\
\hline ALT (IU/l) & $30.40 \pm 23.80$ & $21.10 \pm 15.90$ & 0.119 \\
\hline Uric acid $(\mu \mathrm{mol} / \mathrm{l})$ & $304.70 \pm 70.60$ & $346.50 \pm 82.70$ & 0.066 \\
\hline CpG1 & $80.42 \pm 6.58$ & $82.75 \pm 4.06$ & 0.146 \\
\hline CpG2 & $82.96 \pm 5.16$ & $84.46 \pm 3.68$ & 0.253 \\
\hline CpG3 & $93.08 \pm 9.62$ & $91.75 \pm 5.16$ & 0.553 \\
\hline \multicolumn{4}{|l|}{ Women $(n=48)$} \\
\hline Age (years) & $59.40 \pm 6.40$ & $59.40 \pm 6.40$ & \\
\hline $\operatorname{BMI}\left(\mathrm{kg} / \mathrm{m}^{2}\right)^{\mathrm{b}}$ & $23.49 \pm 2.97$ & $23.25 \pm 1.93$ & 0.747 \\
\hline Total cholesterol (mmol/l) & $5.62 \pm 0.83$ & $5.24 \pm 1.00$ & 0.161 \\
\hline Total triglycerides $(\mathrm{mmol} / \mathrm{l})$ & $1.98 \pm 1.85$ & $1.23 \pm 0.75$ & 0.071 \\
\hline Glucose (mmol/l) & $8.04 \pm 2.22$ & $5.49 \pm 1.20$ & 0.000 \\
\hline ALT (IU/l) & $19.80 \pm 8.60$ & $14.80 \pm 4.80$ & 0.019 \\
\hline Uric acid $(\mu \mathrm{mol} / \mathrm{l})$ & $273.90 \pm 68.30$ & $254.60 \pm 75.00$ & 0.357 \\
\hline CpG1 & $84.79 \pm 3.39$ & $84.67 \pm 4.50$ & 0.914 \\
\hline CpG2 & $84.92 \pm 5.09$ & $86.13 \pm 2.86$ & 0.316 \\
\hline CpG3 & $92.50 \pm 6.07$ & $92.63 \pm 2.89$ & 0.928 \\
\hline
\end{tabular}

${ }^{a} \mathrm{n}=39$ (22 diabetics vs. 17 non-diabetics), ${ }^{\mathrm{b}} \mathrm{n}=47$ (24 diabetics vs. 23 non-diabetics). SE, standard error; ALT, alanine aminotransferase; BMI, body mass index.

may be increased further in the impaired glucose tolerance (IGT) stage, however, subsequently, at the diabetic stage, $\beta$-cell mass is markedly reduced $(10,13)$. IRS proteins are a common element of the insulin/IGF-signaling pathway for peripheral insulin response and pancreatic $\beta$-cell growth and function (10). IRS-1 is important in the insulin action pathway including the activation of related kinases and the subsequent increase in glucose transport $(14,15)$. It has been demonstrated that the unbalanced expression of IRS-1 is involved in the pathogenesis of T2D and obesity (12). In this study, we investigated the role of IRS-1 DNA methylation in T2D. This study provides new information regarding epigenetic regulation of IRS-1 in T2D.

Findings of this study suggest that there was a difference in the DNA methylation level of the IRS- 1 promoter between genders (Table III). The methylation levels of CpG1 and CpG2 were higher in females than in males. The relatively higher DNA methylation status of the IRS-1 promoter in females may be ascribed to the long-term exposure to estrogen. Recent studies have demonstrated that long-term estrogen exposure was responsible for DNA methylation patterning and epigenetic silencing during tissue development in vitro, and in animal models (16-19). In addition, nutritional status has also been demonstrated to be involved in the mechanism for epigenetic regulation $(6,20)$. A chronic, high-fat diet in rat fathers has been associated with the mutation in the promoter methylation status of their female offspring $(6,20)$.

The aim of this study was to explore the unknown relationship between the $\mathrm{CpG}$ methylation levels in the IRS- 1 promoter and the risk of T2D and the exact role of $I R S-1$ epigenetics in this metabolic disease. The results showed no significant difference in the methylation levels of the IRS-1 promoter between the controls and the T2D patients (Table IV). It is notable that although there was a positive gender-specific difference in $I R S-1$ promoter methylation levels among total subjects, a negative connection was observed in the gender-dependent analysis (Table V). These results indicated that the DNA methylation mechanism of the gene promoter may not play a significant role in the epigenetic regulation pathway of IRS-1 expression. It was reported that $I R S-1$ gene variations were associated with the risk of T2D (12) and an increased risk of a major adverse cardiovascular event $(11,12,21)$. Furthermore, the expression of IRS-1 may be target-regulated by miR-126 which inhibits IRS-1 translation (22). These diversified regulatory pathways of IRS-1 biological function may be why the DNA methylation status of this gene promoter exerts no significant effects on the development of T2D.

In conclusion, findings of this study suggest that the DNA methylation levels of the IRS- 1 promoter in blood are not related to the occurrence of $\mathrm{T} 2 \mathrm{D}$. This finding contributes to 
the understanding of the epigenetic value of T2D candidate genes such as $I R S-1$. The negative result may be helpful to guide future gene-based treatment strategies and avoid developing non-functional genetic drugs. Additional studies are required in order to identify the epigenetic regulation network of IRS-1 pathway in T2D.

\section{Acknowledgements}

This study was supported by the grants from National Natural Science Foundation of China (31100919), Natural Science Foundation of Zhejiang Province (LR13H020003), Ningbo Social Development Research Projects (2012C50032) and the K.C. Wong Magna Fund in Ningbo University.

\section{References}

1. Shaw JE, Sicree RA and Zimmet PZ: Global estimates of the prevalence of diabetes for 2010 and 2030. Diabetes Res Clin Pract 87: 4-14, 2010

2. Travers ME and McCarthy MI: Type 2 diabetes and obesity: genomics and the clinic. Hum Genet 130: 41-58, 2011.

3. McCarthy MI: Genomics, type 2 diabetes, and obesity. N Engl J Med 363: 2339-2350, 2010

4. Stolar M: Glycemic control and complications in type 2 diabetes mellitus. Am J Med 123: S3-S11, 2010.

5. Volkmar M, Dedeurwaerder S, Cunha DA, et al: DNA methylation profiling identifies epigenetic dysregulation in pancreatic islets from type 2 diabetic patients. EMBO J 31: 1405-1426, 2012

6. Barres R and Zierath JR: DNA methylation in metabolic disorders. Am J Clin Nutr 93: S897-S900, 2011.

7. Bird A: Perceptions of epigenetics. Nature 447: 396-398, 2007.

8. Villeneuve LM and Natarajan R: The role of epigenetics in the pathology of diabetic complications. Am J Physiol Renal Physiol 299: F14-F25, 2010.

9. Toperoff G, Aran D, Kark JD, et al: Genome-wide survey reveals predisposing diabetes type 2-related DNA methylation variations in human peripheral blood. Hum Mol Genet 21: 371-383, 2012.
10. White MF: IRS proteins and the common path to diabetes. Am J Physiol Endocrinol Metab 283: E413-E422, 2002.

11. Angiolillo DJ, Bernardo E, Zanoni M, et al: Impact of insulin receptor substrate-1 genotypes on platelet reactivity and cardiovascular outcomes in patients with type 2 diabetes mellitus and coronary artery disease. J Am Coll Cardiol 58: 30-39, 2011.

12. Sesti G, Federici M, Hribal ML, et al: Defects of the insulin receptor substrate (IRS) system in human metabolic disorders. FASEB J 15: 2099-2111, 2001.

13. Fernandez-Valverde SL, Taft RJ and Mattick JS: MicroRNAs in $\beta$-cell biology, insulin resistance, diabetes and its complications. Diabetes 60: 1825-1831, 2011.

14. Araki E, Lipes MA, Patti ME, et al: Alternative pathway of insulin signalling in mice with targeted disruption of the IRS-1 gene. Nature 372: 186-190, 1994

15. Rondinone CM, Wang LM, Lonnroth $\mathrm{P}$, et al: Insulin receptor substrate (IRS) 1 is reduced and IRS-2 is the main docking protein for phosphatidylinositol 3-kinase in adipocytes from subjects with non-insulin-dependent diabetes mellitus. Proc Natl Acad Sci USA 94: 4171-4175, 1997.

16. Bredfeldt TG, Greathouse KL, Safe SH, et al: Xenoestrogeninduced regulation of EZH2 and histone methylation via estrogen receptor signaling to PI3K/AKT. Mol Endocrinol 24: 993-1006, 2010.

17. Christensen BC, Kelsey KT, Zheng S, et al: Breast cancer DNA methylation profiles are associated with tumor size and alcohol and folate intake. PLoS Genet 6: e1001043, 2010.

18. Li L, Lee KM, Han W, et al: Estrogen and progesterone receptor status affect genome-wide DNA methylation profile in breast cancer. Hum Mol Genet 19: 4273-4277, 2010.

19. Starlard-Davenport A, Tryndyak VP, James SR, et al: Mechanisms of epigenetic silencing of the Rassfla gene during estrogen-induced breast carcinogenesis in ACI rats. Carcinogenesis 31: 376-381, 2010.

20. Ng SF, Lin RC, Laybutt DR, et al: Chronic high-fat diet in fathers programs $\beta$-cell dysfunction in female rat offspring. Nature 467: 963-966, 2010.

21. Martinez-Gomez LE, Cruz M, Martinez-Nava GA, et al: A replication study of the IRS1, CAPN10, TCF7L2, and PPARG gene polymorphisms associated with type 2 diabetes in two different populations of Mexico. Ann Hum Genet 75: 612-620, 2011.

22. Zhang J, Du YY, Lin YF, et al: The cell growth suppressor, mir-126, targets IRS-1. Biochem Biophys Res Commun 377: 136-140, 2008. 